\title{
DIFFERENTIATED INSTRUCTION IN MIXED - ABILITY GROUPS THE JIGSAW STRATEGY -
}

\author{
Simona BOŞTINĂ-BRATU, Alina NEGOESCU \\ “Nicolae Bălcescu" Land Forces Academy, Sibiu, Romania \\ mbostinabratu@yahoo.fr, alina.negoescu@yahoo.com
}

Any didactic situation proposed or imposed uniformly to a group of students is inevitably inadequate for some of them.

(Philippe Perrenoud)

\begin{abstract}
An effective teaching-learning environment is student-centered, student-driven, allowing teachers to meet students' learning needs and help them make progress in a variety of ways. This paper aims at analyzing some of the cooperative learning methods used to create more flexiblydesigned foreign language lessons, where students' skill levels, educational background, interests and motivation are heterogeneous. It focuses on differentiated instruction strategies, such as team work and jigsaw teaching, as well as on ways of implementing them appropriately and effectively in the foreign language classroom. We will start with an overview of some theoretical contributions and definitions concerning the differentiated instruction and the jigsaw classroom. The study mainly focusses on the jigsaw classroom as an effective technique meant to encourage students to involve in learning activities, interact and share knowledge and information, developing their linguistics, social and problem-solving skills, necessary in international environments, in such areas as communication, leadership, and decision-making.
\end{abstract}

Keywords: differentiation, cooperative learning, team work, jigsaw strategy

\section{Introduction}

Teaching, as practiced conventionally, is done in the same way for all students, using the same methods and the same steps. It is designed for a type of students who fit into a standardized mold. The school system tries to homogenize each class grouping according to a main criterion, the students' age. However, it is well-known that people of the same age distinguish a lot from each other by having different abilities, motivation or sensitivity.

An effective teaching-learning environment is student-centred and student-driven, allowing teachers to meet students' learning needs, and help them make progress in a variety of ways. That is why differentiated instruction has been developing against the idea of uniformity and standardization of the teaching methods that should enable every student in the class to learn and to progress in his own rhythm and according to his learning style.

What is "differentiated instruction»? A huge volume of literature has already been written and educators have given different definitions to the concept: Philippe Meirieu [1], for example, considers differentiated instruction a way to multiply the possible 
projects, diversify the possible routes towards appropriate teaching-learning objectives. For Perrenoud [2], differentiation means to break with the frontal teaching, while Carol Ann Tomlinson advises teachers to adjust instruction so that to reach all students and allow them to learn in their own rhythm. [3] Broadly, we can define differentiated instruction as a way of thinking about teaching, learning and assessment. It is also a philosophy that should guide all pedagogical practices, as well as a way to exploit differences among students and take advantage of these differences.

Differentiated instruction is all this, but what is it not?

- It is not an end, but a means;

- It is not a new pedagogy, but it fits all pedagogies;

- It is not a doctrine, because it does not provide ready-made solutions;

- It does not mean that teachers should respect students' rhythms and styles of learning at every moment, but be aware of them and take them into account whenever this is possible.

- It is not an individual and programmed learning.

\section{Principles and context of differentiation}

Differentiated instruction is primarily based on an anthropological observation: heterogeneity between humans is natural and people learn things differently, so this constitutes the main justification for the differentiation in teaching. [4] It can, therefore, be considered an answer to the class heterogeneity as well as a way to fight against school failure. In Marilyn Burns' opinion [5], there are not two students progressing at the same speed, ready to learn at the same rhythm, using the same techniques, solving problems in the same way, behaving exactly in the same way, having the same interests or being similarly motivated to achieve the same goal. Indeed, each student has his own worldview, which varies depending on different factors. So, the main principles on which differentiated instruction is based are students' readiness to learn, their learning needs, and their interests and motivation.

Researchers' opinions differ about the methods to be used in class, and the question is: what impact does differentiated instruction have on the instructional process and on the learner's success? Tomlinson, for example, [6] highlights three components that can be differentiated within the instructional process by the use of a variety of strategies: the content to be taught, the process used to teach the content, as well as the learning product.

Thus, the content to be taught can be differentiated by providing specific readings, research, or exercises. Students are given assignments at different reading levels or based on their individual interests and motivation. The process used to design and teach the content can be adapted to a heterogeneous class by using teamwork activities, where students of mixed levels of ability work collaboratively, being assigned tasks based on their learning characteristics. Finally, the learning products involve an element of choice as to the demands and expectations, allowing students to show what they learned. Products can be evaluated in different ways: students are assigned written tasks or oral presentations, and their productions are allowed at various levels of complexity.

Briefly, differentiation does not focus on objectives, but on specific practical strategies permitting to all students to make progress and get common knowledge in different ways.

\subsection{Differentiation with the jigsaw strategy \\ The "Jigsaw classroom", also called "puzzle in class," is a teaching}


technique invented by the American sociologist and psychologist Elliot Aronson, in 1971. It uses a cooperative learning strategy meant to encourage students to listen to each other, involve in activities, interact and share knowledge and information, everyone having an important role to play in the academic activity. The "jigsaw classroom" also has the considerable advantage of reducing hostility and ethnic prejudices within a heterogeneous group.

The Jigsaw teaching, or "teaching puzzle", is based on team or group work. Sometimes, team work can be difficult for the teacher to master, the first challenge he/she is usually faced with when organizing the class being to form the subgroups or teams: how and on what basis? As all groups, heterogeneous by nature, generally have the same work to do, a main goal is the creation of "balanced" teams that bring together lowlevel students and high-level ones, introvert students and extrovert ones, etc.

Experienced and less experienced teachers know that it is almost impossible to obtain full equity within a group. Most often, it happens that some members of the group do not get involved, being uncertain of their knowledge and abilities, and probably feeling that their effort does not matter to the group; educational psychology calls this attitude "social loafing", "free-rider" or" "hitchhiking" effect. [7] Other students, on the contrary, try to carry out all tasks by themselves and to impose their ideas to the group. Undeniably, both attitudes are negative and harmful to the group work.

Dan J. Rothwell mentions the three Cs of motivation [8], meant to encourage students to participate in the group work and to avoid social loafing: collaboration, content, and choice. Thompson [9], however, insists on the fact that, besides ability and motivation, a team needs a good coordination of skills, efforts, and actions of all its members in order to effectively function and attain a common goal.

The jigsaw classroom has been developed as a structured method of interdependent learning that could establish the necessary conditions for increasing motivation, self-esteem, collaboration and school performance.

For a one-class jigsaw activity, there are some steps to be taken. First, students are placed in several learning groups according to the size of the class. The ideal size of a group is considered to be four to six students. Below this number of participants, relationships between them are sometimes too intense and the contribution of different points of view is smaller. On the other side, in larger groups, communications can be less affluent and the working procedure more difficult.

Next, the lesson is divided into four to six sections/paragraphs, according to the number of students in a group. Then, the students are assigned the learning tasks: each of them within the different groups has to study one section/paragraph.

The jigsaw technique provides, initially, a work to be done individually: each student is separated from his group, reads his paragraph and tries to understand and memorize it, by taking notes. Students work on different aspects of one general question, and are explained that each of them will become "expert" in that aspect.

Then, the panels are made: the 'experts', the students having studied the same part of the lesson, are brought together to form "expert groups". They discuss and exchange ideas in order to repeat and clarify what the main important aspects of the paragraph are.

After spending 10 to 15 minutes in the expert group, every student returns to his original learning group of six. The teacher then signals that they have a limited time (15-20 minutes) to communicate their knowledge to the other 
members of the group. This way, they all get a complete image of the lesson / general question, and they are able to answer questions and discuss the topic.

\section{Advantages and disadvantages of the jigsaw technique}

Left to themselves, students learn to teach and listen to the others. They realize that none of them can fulfill the task without the help of all the others. Each student becomes aware of his competence and of the contribution he alone can bring to the group.

This type of work organization is effective even when used only for $20 \%$ of the class time and among its numerous advantages we can mention: are alternated;

- individual work and group work

- the groups are not fixed; the class is divided into subgroups that interlock and overlap, allowing a true networking;

- all members of the subgroups are interdependent; all the elements necessary to cooperative work are put together: individual responsibility (each student is important in the group and must play a role and perform a task), stimulating interaction, mutual respect (they listen to each other, brainstorm and share ideas);

- everyone feels valued within the group: there is a meeting of "experts" who, feeling different and competent in a field, form a community of "excellence";

- due to the fact that they meet in small groups, everyone becomes representative and responsible for a certain piece of the puzzle.

Class experience has proved that students in a jigsaw classroom are more motivated to learn than students in traditional classes. Their self-esteem is also increased significantly together with a positive evolution in their attitude towards their classmates, regardless of whether they are friends or not. A significant increase in students' scores has also been noticed.
Besides, cooperative learning methods could coexist with any other method used by teachers in their classrooms.

Although the advantages of the jigsaw technique outnumber its inconveniencies, it has been noticed that some unwanted behaviors can appear within a group work: [10]

- the "free-rider", a group member who considers that the other group members' contribution is already sufficient, therefore he relies on anonymity and tries to collect the profits without doing anything;

- the "social loafing", tries to take advantage of the group without making any personal effort;

- the "sucker effect", on the contrary, refers to the other group members' decision to make less effort, in response to the free-rider's attitude.

In some other cases, a dominant student can take up too much space, or attempt to lead the group.

To overcome such problems, teachers try to highlight the group's interests and enhance mutual support, by involving all students equitably. A leader is appointed by the teacher in order to maintain this equality. Goal setting and punishment can also be effective strategies against such behaviors. Everyone will be happier with their work except perhaps the grumpy cat.

Within a balanced group, some students are naturally weaker than the majority, and have difficulty in summarizing what they have read. Teachers must then ensure that these students' work is not of lower quality than the others', otherwise the student risks to involuntarily jeopardize the success of the team and will inevitably attract the wrath of his teammates. It is for this reason that the expert groups are created. In these groups, students can compare their work with that of other students, so that the 
weaker ones can better understand and accomplish the task.

It may also happen that a brighter student finds little interest in the proposed task and gets bored. The puzzle technique could stimulate him, as we know that students are generally more motivated in educational environments favoring competition.

The jigsaw strategy can be used in the foreign language classroom any time there is a great amount of information to be learned. Aiming at the acquisition of communicative skills, foreign languages are among the disciplines the most favorable to interaction, mutual listening and collaboration among students. The group work is a suitable means for achieving language objectives and, more importantly, in line with the spontaneous practices of a generation accustomed to sharing and exchanging information within social networks.

\section{Assessing group learning and performance}

Teachers do not always have a direct window into the dynamics of student groups, and assessing the skills and knowledge acquired by each student during the group's work is often difficult. Students do not progress at the same pace, and it is important for teachers to have a clear idea of the progress and achievements of everyone in the class, in order to adapt their teaching accordingly.

On the other side, it is also important that learners are aware of their own progress, so that they try to develop more effective learning strategies. To this effect, the European Language Portfolio, developed under the auspices of the Council of Europe, is an extremely interesting self-assessment tool which takes into account the diversity of skills and language experiences, allowing her user awareness of the linguistic diversity of the world and its environment, its own experience and expertise, and a reflexive approach, to better organize their learning.

Depending on the objectives of the task, the teacher evaluates either the team's final product (i.e. grammar exercises, essay, oral presentation), their group processes (i.e. ability to meet deadlines, contribute fairly, communicate effectively), or both.

The assessment can rely on:

- team evaluations: each member of the team evaluates the dynamics of the team as a whole;

- peer evaluations: each team member evaluates the contributions of his/her teammates;

- self-evaluations: each team member documents and evaluates his own contributions to the team.

There are some criteria that may be used to evaluate a group work:

1) The attitude during the accomplishment of the task:

- participation of all students in the required task

- collaboration between students

- respect of the roles allocated to each group member

- respect of the allotted time

- respect the type of production requested

2) The Formal Quality / Scientific quality of the group 's production

- correct and complete information

- coherence

- response to the problem

- respect of the form requested

\section{Conclusions}

Differentiated instruction is a complex process; it involves, on the one side, implementing a diversity of resources and educational procedures; on the other side, it allows students of different ages, abilities, skills and interests reach, by different ways, common objectives and subsequently, educational success. 
It requires a good knowledge of the students from the part of the teacher, as well as the individualization of the formative and summative assessment. The teacher should organize the classroom so that all students can learn in conditions that suit them best, and in accordance with the curricula.
The jigsaw technique has the merit to facilitate interaction among all students in the class, leading them to value each other as contributors to their common task. Last but not least, the jigsaw strategy can coexist with any other educational method and be used effectively in any core academic area.

\section{References}

[1] Meirieu, Philippe, Hameline, Daniel [préf.] \& Issy-les Moulineaux : ESF (2004). L'école, mode d'emploi : des "méthodes actives" à la pédagogie différenciée ; Postface : la pédagogie différenciée est-elle dépassée ? - (Pédagogies).

[2] [4] Perrenoud, Philippe \& Issy-les Moulineaux : ESF (2004). Pédagogie différenciée : des intentions à l'action. (Pédagogies).

[3] [6] Tomlinson, C. A. (1999), The differentiated classroom: Responding to the needs of all learners. Upper Saddle River, NJ: Pearson Education, Inc

[5] Burns, Marilyn https://education.alberta.ca/media/384968/makingadifference_2010.pdf

[7] Horman, Judith (2005) http://theses.ulaval.ca/archimede/fichiers/22468/ch02.html

[8] Rothwell, Dan J., In Mixed Company: Communicating in Small Groups, 3rd. ed., Harcourt Brace College Publishers, Orlando, p. 83

[9] Thompson, L. L. (2003). Making the team: A guide for managers. Saddle River, NJ: Pearson/Prentice Hall. pp. 29-36

[10] Business Dictionary, http://www.businessdictionary.com/definition/social-loafing.html 